\title{
Borders (in between): A City within a City Decoding Different Morphologies of Fragmented Housing
}

\author{
Hatice Kalfaoglu Hatipoglu, Seher Beyza Mahmut* \\ Faculty of Architecture, Ankara Yildirim Beyazit University, Ankara, 06110, Turkey
}

Received July 22, 2020; Revised August 12, 2020; Accepted August 20, 2020

\begin{abstract}
Cite This Paper in the following Citation Styles
(a): [1] Hatice Kalfaoglu Hatipoglu, Seher Beyza Mahmut, "Borders (in between): A City within a City Decoding Different Morphologies of Fragmented Housing," Civil Engineering and Architecture, Vol. 8, No. 5, pp. 880 - 889, 2020. DOI: 10.13189/cea.2020.080515.

(b): Hatice Kalfaoglu Hatipoglu, Seher Beyza Mahmut (2020). Borders (in between): A City within a City Decoding Different Morphologies of Fragmented Housing. Civil Engineering and Architecture, 8(5), 880 - 889. DOI: 10.13189/cea.2020.080515.
\end{abstract}

Copyright $\bigcirc 2020$ by authors, all rights reserved. Authors agree that this article remains permanently open access under the terms of the Creative Commons Attribution License 4.0 International License

\begin{abstract}
Cities act as living organisms that bring people together and contain different social aspects in heterogeneity. When people with similar lifestyles regarding income and culture come together in enclosed groups, places are divided into physical and social gated communities which create unseen borders between different groups of people. The aim of this study is to demonstrate the effects of segregated spaces separated by physical or social borders in the city. Firstly, gated communities, which are presented as contemporary walled island, will be discussed by focusing on the concept of segregation as a result of these borders in relation with morphology. Accordingly, an evaluation framework has been developed on three main scales, which are based on the Conzen's classification of space, to create a systematic overview to analyze the segregated morphology. Sinpaş Ege Valley Housing Project and its surrounded slums, which were located on the Dikmen Valley of Ankara having a different typology and borders in-between, is chosen as a representative case of the aforementioned segregation to analyze the effects of these unseen borders on space typologies, people's space usage and activity patterns.
\end{abstract}

Keywords Segregation, Neighborhoods, Housing Quality, Gated Communities, Urban Space, Urban Morphology

\section{Introduction}

The city, which integrates people through the development of social interactions in everyday life, is a social entity [1]. Habitat selection and choice of particular environmental quality cause a clustering in city so that the city becomes a set of areas of different groups which tend to define themselves in terms of "us" and "them" [2]. A clustering process tends to occur in cities based on perceived homogeneity, differing interpretations of environmental quality, lifestyles, symbol systems and defenses against overload and stress. Although the homogeneity which appears because of the tendency of similar people in an area is arguable for urban life, settling in this way occurs inevitably [2].

Today, people's social, cultural and economic relations define their consumption habits define their consumption characteristics. The space is also defined as a consumption object which provides a place to the individual. For this reason, economic restructuring triggers changes in the global city's structure [3]. As a consequence, while the city is being spatially fragmented; the society is also fragmented by socio-economic and cultural divisions. These two processes of fragmentation in space and social structure are mutually interdependent. As a result of these processes, the city becomes a segregated organism and is divided by social groups that cause conflict.

Urban morphology is the study of the shape and form of settlements. Morphological structure describes urban elements as physical features of cities and their hierarchy 
on different scales, from architectural elements in a room, dwelling, building storey or building, to urban elements such as façades, buildings, streets, routes, neighborhoods and urban regions [4]. Every single detail of the city influences morphology of spaces. According to different segregated parts in city, morphologic pattern inherently changes.

This study aims to analyze the morphological components of urban segregation in different typologies to highlight the fragmentation of urban space through different kind of social entities as a result of physical/social borders. In order to demonstrate the spatial and social effects of this fragmented parts of the city, segregation is discussed in relation with morphology.

\section{The Scope of the Study and Conceptual Framework}

\subsection{Fragmented Parts of Cities}

Segregation is the separation of one group forum another which occurs in both formal and informal way. This division depends on indicators of difference, where gender, race, ethnicity, religion or social class, is used as the foundation for confirming a dissimilarity between groups and populations [5]. Although non-geographical platforms are the scenes of the articulation between social groups, [6], urban segregation is saliently spatial.

People who have the same social backgrounds with similar characteristics show a tendency to be a group in themselves and define their own community/territory. However, this situation becomes visible due to intensification of social differences over time which causes a social segregation. Andersen defines social segregation as follows: "Social segregation is the spatial segregation of ethnically or socially different groups, leading to increased social and cultural differences between groups" [7]. There must hence be some cultural homogeneity and execution of unwritten rules, symbols and behavior [2].

Social and spatial segregation are often discussed together. Social segregation causes people to cluster in certain places of the city which causes spatial segregation. Thus, areas that can be defined as enclave have been created within the city, which is a small, distinct area or district where an insular group of people live [8]. Besides, the urban enclave is a way to shape places in cities where like-minded people can find each other and be part of the greater whole [9]. Race, income, class, ethnicity are parts of the categories of it [10]. These categories can be grouped under certain headings. For instance, according to Marcus, enclave grouping can be classified as outcast/classic ghetto, immigrant and cultural enclaves and citadel [11]. Outcast ghetto is a community of socially excluded people. Immigrants and cultural enclaves are areas of the same ethnic origin, similar lifestyles and mindset. The Citadel is the closed communities formed by the upper income group's spatial separation and self-isolation. In all these cases the key process is habitat selection based on values and environmental preferences. Consequently, group identity is reinforced by clustering, manifested by environmental symbols and enclosed by boundaries [2].

There are many reasons behind these disintegrations, which occur voluntarily or compulsorily [12] in the city and become physically observable. The reason for spatial differentiation is due to the desire of people to live with the people they see equivalent. In general, segregation of the upper classes is based on voluntarism, while the lower classes are due to necessity.

The enclaves formed by the upper income group are also called the gated community. Gated communities, provide security and exclusivity to its residents through a combination of physical barriers, surveillance, security guidance, and community self-regulation of architecture and behavior [13]. In literature, the main reasons for moving to a gated community are referred as the fear of crime, violence in urban environment, the expectancy to get better habits and lifestyle, the escape from the city problems which are caused by low-income people asking for money [1]. Besides, the increasing income inequality between the upper and lower sections of the society is a factor supporting the formation of the gated community.

There are different perspectives that discuss whether spatial segregation has positive or negative effects on city. For former, people welcome the similar groups living together because they are easier to mingle with, togetherness makes people feel more belonging to the place and create reliable spaces by establishing a social network. The process of clustering helps cultures survive and provides appropriate organizations of meaning and communication. Likewise, inhabitants share symbols and apply unwritten rules which were shaped by their behaviors [1]. As a result of having fixed and defined areas, the problems and the level of stress are minimized. As well, homogeneity seems to increase neighboring more than heterogeneity [2]. According to the latter approach, social segregation that brings spatial segregation in the city is opposite to the nature and heterogeneity of the city. Keeping people with similar backgrounds and cultures in borders will create segregated communities which will not be able to provide an integration of a community which we need [1]. Fewer job opportunities, intense discrimination, scarcity of public services and infrastructure are the examples of various limitations which are imposed to certain population groups. With the guidance of several studies, disadvantaged urban populations would benefit from a more non-segregated distribution of people in urban spaces [6]. The preference of new living spaces by groups which are gradually separated and differentiating from each other plays a role in the transformation and alienation which reduces sense of belonging of people in cities [14]. 


\subsection{Morphology of Segregation}

The city is defined by and structured through the heterogeneity of the differences[15]. According to Lefebvre [16], the form is produced by the diversity. Besides, Brotchie et al. [17], describes the urban form as the pattern of residential and non-residential activities in urban and their reflections on which accommodates them. These discussions are in the scope of the researches in urban geography and interurban/intraurban relations which study spatial aspects of urban development. In inter-urban relations, urban areas are studied in terms of their morphology, which is the study of the form and shape of settlements [18]. Clark describes urban morphology as the study of the form in systematic way, plan, shape, structure and functions of the built fabric of cities/towns and of the origin and the way in which this fabric has changed over time [17]. In this systematic approach, the elements of the urban morphology have been described as plots, buildings, use, streets, plans and townscapes [19].

Studies on morphology have been carried out with different perspectives. For long years, effective methods of explaining and exploring the physical form/shape of urban spaces, have been developed by urban morphologists. [20]. M.R.G. Conzen was one of the important names that guided morphological research. In some of the current studies today, the systematic established by his researches has still been used. Conzen [21] asserts a tripartite division of urban form into first, the town/ground plan; secondly, building; and thirdly, land and building utilization, which is the intersection of both [22]. Morphological regions are shaped and differentiated according to these divisions.

When looking at the city or the neighborhood from top view, the differences seen in morphology which point to close and homogeneous islets that occur within the heterogeneity of the city. It shows that residents in one place have different relationships and systems than others. Opportunities and limits in these environments affect the satisfaction and behavior of people; therefore, it directly influences the general health, happiness and welfare of the individual/neighborhood and society [23]. As a consequence, a cluster of distinct segregation emerges at every scale.

\section{Materials \& Methods}

It has been developed a framework to evaluate the effects on different morphology. This evaluation, which aims to create a systematic approach to assessing these components, is based on literature review and Conzen and Gehl's concepts. Table 1 shows the evaluation criteria of different morphologies. Conzen's classification of scales underlies the indicators. These scales are further developed by means of sub indicators in each layer in order to understand/analyze the codes of morphology which create segregation in different scales and in more details. Table 1 shows the evaluation criteria of different morphologies.

Sinpaş Ege Valley Housing Project and its surrounded slums, which were located on the Dikmen Valley of Ankara having a different typology and borders in-between, is chosen as a demonstrative case study for the evaluation. The evaluation has been conducted by using observations on the field and morphological analyses according to the defined indicators of the evaluation.

Table 1. Definition Criteria of Different Morphologies

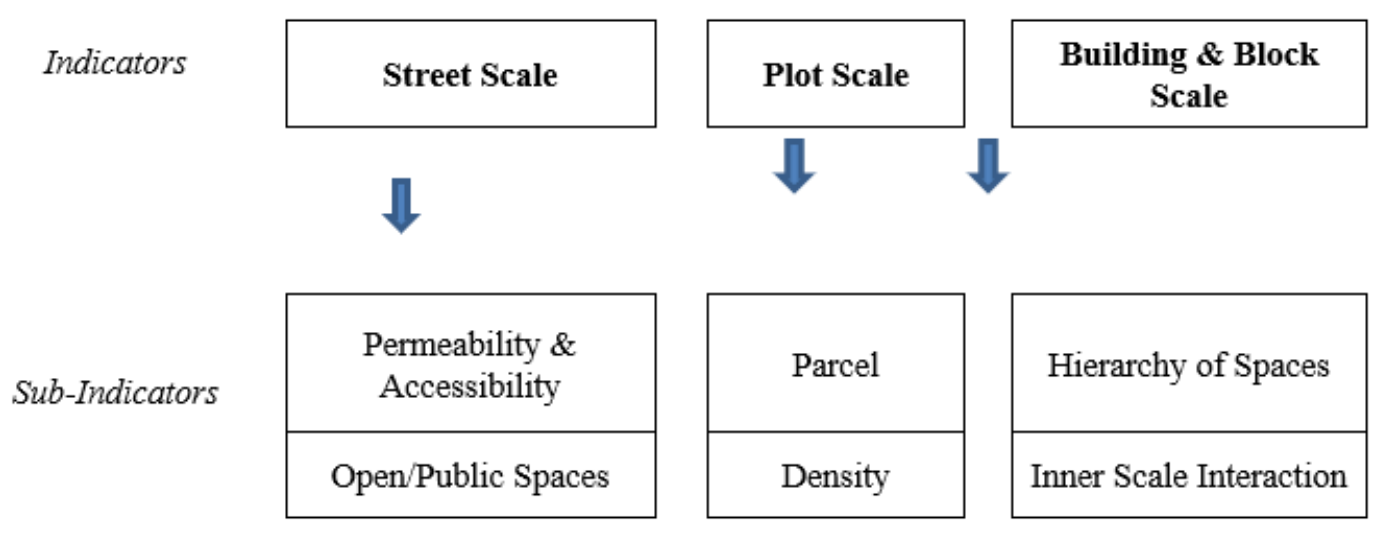




\subsection{Case Study: Sinpaş Ege Valley Housing and Its Surrounding Slums}

Sinpaş Ege Valley Housing Project (SEVHP) has been studied as an example of gated communities and the morphological differences between SEVHP and surrounding slums has been analyzed.

The project area (Figure-1) is located on the southeast of Dikmen Valley in the region known as Yukarı Dikmen Neighborhood in Çankaya district of Ankara. Urban transformation projects have been completed in stages in the northern parts of the valley. However, there are several advertisements from different construction companies in the region and it is estimated that projects such as SEVHP will be shaping the general design of the district by demolishing the slums in the near future.

SEVHP is a housing project that attracts attention with 889 flats and 49-storey tower and 5 other closed blocks consisting of different floor numbers. The project annunciations started at 2016, and today it has almost been done. It offers different activity areas/facilities and housing types to privileged people. The most important feature of the project which is emphasized is to enable coast life in Ankara. However, there are security guards at the entrance and the area is monitored by cameras during 24 hours of each day in a week. Moreover, it fits to the definition of walled island because it is surrounded by walls at the same time.

There are approximately 85 slums around SEVHP and they are located/designed in the land in accordance with the topography. Most of them are in damaged condition. Although there are no walls at the entrance of the area, there is a perceptual wall as a symbolic barrier built by the inhabitants of these slums against foreigners coming from outside. Additionally, these slums have created a dynamic structure in itself.

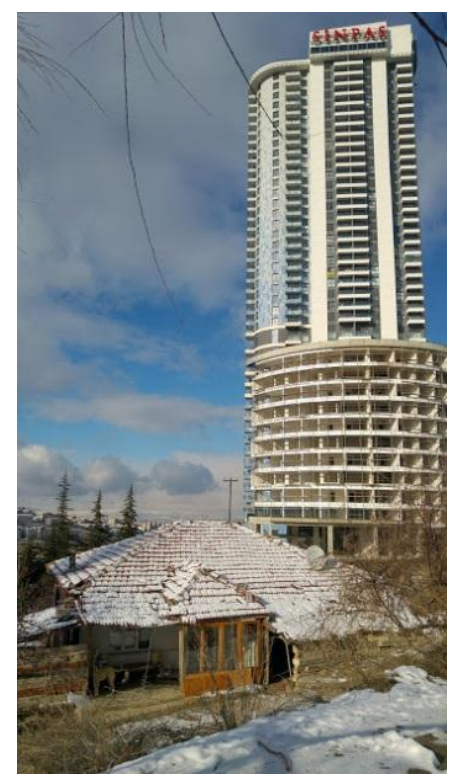

Figure 1. A view from the field

\section{The Evaluation Framework of Different Morphologies}

Analysis of the morphological components of urban segregation has been categorized into three basic elements of the city plan following the Conzen classification: streets, parcels and buildings [21]. Each of these elements is interrelated each other. His concept of the composite city plan defines variations in forms, uses and configurations found in different parts of the city. This plan consists of different units called unit plans and these are best observed in street, parcel, building size and forms [24]. Unit plans also contribute to the stratification of the urban landscape [25].

\subsection{Street Scale}

According to Conzen [21], street represents open spaces covered by street lines and reserved for the transition of pedestrian and vehicle traffic. The composition of these adjoining and interdependent spaces within an urban area, have been constituted the street system. The street system is one of the irrevocable parts of urban design. Efficient and distinctive use of urban areas can be created as a result of plausible and well-considered street plans.

\subsubsection{Permeability and Accessibility}

Street pattern contributes to creating permeable spaces. Permeability is a crucial urban design element for perception of spaces. It provides movement and accessibility opportunities in an area. According to Carr, there are three different accesses which influence the permeability of a place [26].

- Visual Accessibility (Visibility): People can see into a space before they enter it.

- Symbolic Accessibility (Symbols): Cues (symbols) can be animate or inanimate (someone's entrance to space is threatening or not, a feeling).

- Physical Accessibility: Space is physically available to the public.

\subsubsection{Open/ Public Spaces}

Public spaces are irrevocable part of urban system for citizens. While Wilson [27] introduces his hypothesis which focuses on an instinctual connection between the human self and other living organisms, he has claimed that urban public spaces offer clear health benefits for citizens by getting fresh air and exercising. Also, humans seem to need both social contacts with others and some access to greenery in order to maintain psychological balance to be provided by good public spaces [28].

When the public spaces of both territories are analyzed, it is observed that there are 5 main open spaces in the vicinity of the district but none of them are inside the slum settlements. In other words, these open spaces mostly serve to the housing blocks around. However, there are 
quasi-public spaces inside SEVHP, which are preferred more than the surrounding public spaces by the inhabitants of the gated community.

Urban designers influence the patterns of human activity and daily/social life by shaping the built environment. Similarly, environmental opportunities obviously affect what people can and cannot do [26]. Jan Gehl has categorized the outdoor activities in public areas under three headings; necessary activities, optional activities, and social activities [29].

- Necessary Activities: These are imperative activities and occur whatever physical conditions are, like going to school, waiting for a bus.

- Optional Activities: most of the recreational activities that are especially pleasant to pursue outdoors are found precisely in this category of activities. So, it is vital in connection with physical planning. Like walking to get some fresh air, it can be achieved if time and space make it possible.

- Social Activities: This type is based on the existence of others in public spaces. In this context, only those activities that occur in publicly accessible areas are examined like children at play, greetings and conversations etc.

Consequently, Gehl supports that when outdoor areas are of poor quality, only strictly necessary activities can be occurred [29].

\subsection{Plot Scale}

The areas which are unoccupied by streets or in part of street blocks can be defined as a plot [21]. Each block contains one or more land parcels and each of them is a land use unit. It is above the ground and defined by boundaries physically.

\subsubsection{Parcel}

Conzen has contributed "burgage cycle" term to literature. The cycle implies changes in the number of buildings in one parcel. The initial structure within the parcel is the addition of new buildings in parallel with the increase in construction activities in the city over time, and the number of these structures, such as economic breakdowns, natural disasters, new zoning rules and wars, has decreased for several reasons. These changes on the parcel and its structures directly affect the formal structure of the city [24].

\subsubsection{Density}

Changes on the basis of the parcel also have an influence on the density of the area. According to Edward $\mathrm{Ng}$ [30], building density has a complex relationship with urban morphology; it is vital in the shaping of urban form. Creating dense areas produces positive outcomes according to some researchers, while others claimed that it caused a social collapse [30-31]. For instance, increasing urban population leads to a scarcity of land and it is an example of the spatial benefit of multi-storey buildings. However, according to Skjaeveland\&Garling expanded density leads to an increased sense of loneliness and a decreased sense of belonging to a neighborhood [31].

\subsection{Building-Block Scale}

The block-plan of a building is the area occupied by a building and defined on the ground by the lines of its containing walls [21]. It is an essential element of the town plan, loosely referred to as the 'building'. Consequently, interventions on building level, has been also accepted as a morphological element.

\subsubsection{Hierarchy of Spaces}

According to Edward $\mathrm{Ng}$ [30], to learn how people feel about living in high density cities, ratio of people per unit area does not respond to the answer. It is more crucial that the functions in these places and how these are designed in the whole space. In particular, the notion of private, public and semi-public space plays a central role here as Newman has emphasized [32,33].

\subsubsection{Inner Scale Interaction}

There has been substantial interest and study over the years into the relationship between human behavior and urban form $[2,28,30]$. According to Dear\&Wolch, social relations can be constituted through space, constrained by space and mediated by space [34]. Therefore, every physical feature on space has an influence for changing human behavior.

According to Gehl physical arrangement can prevent or promote visual and auditory contact in at least five different ways: walls, distance, speed, level and orientation [29]. If there are no walls between people, people can communicate in small distance, speed in settlement is based on walking rather than driving and houses in the same level and their orientation look each other; The contact between individuals have been promoted.

\section{Results of the Evaluation of Different Morphologies}

\subsection{Street Scale}

In SEVHP, there is a square in the middle of the project area which is enclosed by blocks around it. Inside the walls of the project, it is impossible to perceive this structure as real street system. However, SEVHP as one of the attached walled islands to the streets of the slums which have been shaped organically in harmony with the topography.

When SEVHP and its surroundings are analyzed in 
street scale, SEVHP is in a position that affects permeability in a negative way. Since it has a closed edge of approximately $150 \mathrm{~m}$, which prevents the perception of the Valley and what is happening in the north and disconnects visual interaction. Physical access is also not possible, since the people from outside are not allowed entering the area and entrance is under the control of security personnel and cameras. Likewise, since the area addresses only one group, symbolic accessibility is not possible at this point.

Slums contain more open entries than SEVHP. The streets are shaped to the extent allowed by the topography. No security guidance is required to enter this area. The general housing pattern structure is not formed by big blocks; they are separated from each other and take up small space in the land. In this case, while physical and visual accessibility is provided there is a break in the symbolic accessibility only for those who are strangers. Table- 2 shows the types of accessibility analyzed in both habitats.

Table 2. Types of accessibility provided by habitats (Created by the authors according to Gehl [29] )

\begin{tabular}{c|c|c|c|c}
\cline { 3 - 4 } \multicolumn{2}{c}{} & \multicolumn{3}{c}{3 types of accessibility } \\
\cline { 3 - 5 } \multicolumn{2}{c}{} & Visual & Physical & Symbolic \\
\hline \multirow{2}{*}{ Units } & SEVHP & $\times$ & $\times$ & $\times$ \\
\cline { 2 - 5 } & Slums & $\sqrt{ }$ & $\sqrt{ }$ & $\times$ \\
\hline
\end{tabular}

When the opportunities presented in the case study are examined, it is observed that both groups can bring necessary activities as compulsory, and optional activities occur though under different conditions and at different levels. In SEVHP, attention was paid to the diversity of places where people will come together. However, these places act as private 'club' areas which require membership instead of being a public or 'quasi-public' place. [26]. Slums settlements can only reach parks around neighborhood which are not specific for them. It is obvious that they contain big differences with the SEVHP next to them. In this case, it is possible to say that the social activities that are allowed in SEVHP are higher than those in slums but activities in SEVHP cannot belong to urban life because they have located beyond the walls and serve only their inhabitants with some payment. This situation promotes fragmentation Table 3 shows the activities which are provided by each habitat.

Table 3. Activities Provided by Environment

\begin{tabular}{|c|c|}
\hline SEVHP & Slums \\
\hline Winter Gardens & Recreation Area \\
\hline Shopping Mall & Playground \\
\hline Hobby Atelier & \\
\hline Playground & \\
\hline Sport Area & \\
\hline Beach & \\
\hline Poll & \\
\hline
\end{tabular}

\subsection{Plot Scale}

In the phase from 2013 to 2019 (Figure 2-3), there have been new construction attempts and new zoning plans on the case study site. The current zoning plans promote privatized land-uses/housing like SEVHP which results in the disappearance of small parcels. Cadastral parcel's borders have totally changed. Even if there is an investigation into parcels' shape only, morphological changes can be estimated. Additionally, when figure-ground relations are analyzed, it is obvious that there is a decimation of slums on the site. Slums in SEVHP area are demolished and the new building type has been constructed. When ownership situation and emptiness/abandonment of the area is considered, it is not difficult to assume that there will be new construction projects like SEVHP which totally excludes the heterogeneity of city, not surprisingly.

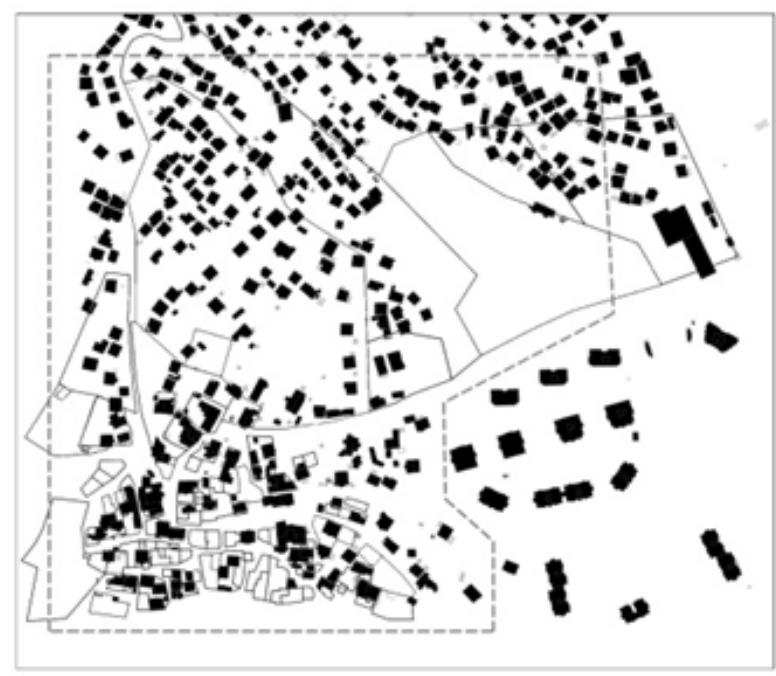

Figure 2. Cadastral parcels and figure ground relations at 2013

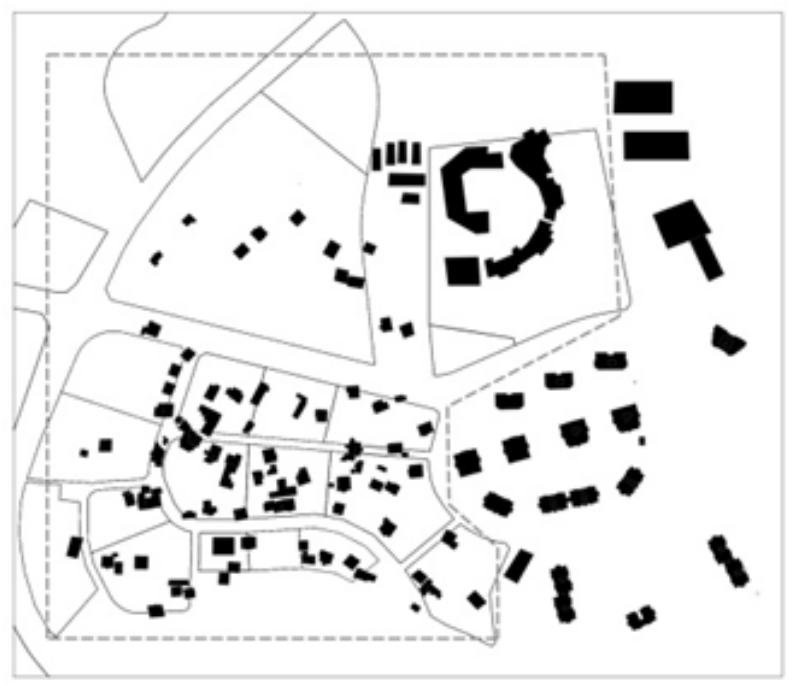

Figure 3. Cadastral Parcels and figure ground relations at 2019 
In the case study, it is obvious that the density of two areas is totally different from each other. Table-4 shows the calculations of density for each area. Slum settlements cover approximately 19 ha of land, while SEVHP covers only 2,6 ha. Moreover, in slum area there is less living unit per meter square than in SEVHP. As expected, in SEVHP plot, there are almost 73 times more people per square meter than slum area. That demonstrates the density differentiation between two different housing types. It is observed that intense units and people on the SEVHP are totally pressed on the blocks, which are not convenient and suitable for the nature of human and nature of neighborhood. On the other side, less dense slum settlements provide a proper human-scale, better interaction of individuals and a more perceivable neighborhood.

Table 4. Calculation of units per square meter \& population per square meter

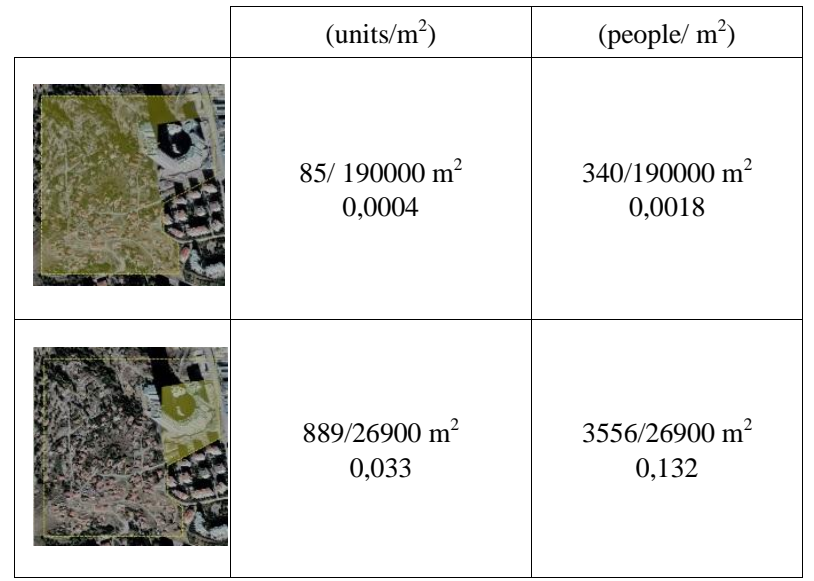

\subsection{Building-Block Scale}

In the area, it is noticeable that there are different types of housing which present different hierarchy of spaces. Table-5 presents the space hierarchy of each type. In slums the lack of semi-private space can be observed. For inhabitants of slums, space hierarchy doesn't respond to the basic needs. People live there to fulfill their shelter needs and there is no consideration of other items like hierarchical space. Although most of slums have not any physical arrangement to promote this hierarchy, there is a sense of space hierarchy perceived when strangers enter the space and this sense develop organically without physical borders. Contrary, SEVHP area is well-designed to provide better conditions for its settlers. All hierarchical level was applied, also because of its gated functions; area automatically gives a chance as semi-private usage for its inhabitants. In Slums this hierarchy is provided in an organic way, but in SEHVP the aim was to create a hierarchy against the non-inhabitants. However, according to Newman because of the height and density of such housing types, the designed semi-private zones have had the characteristic of a public zone and even the circulation routes inside the housing have been used as streets because of the intensity of the human use [32].

Table 5. Hierarchy of Spaces

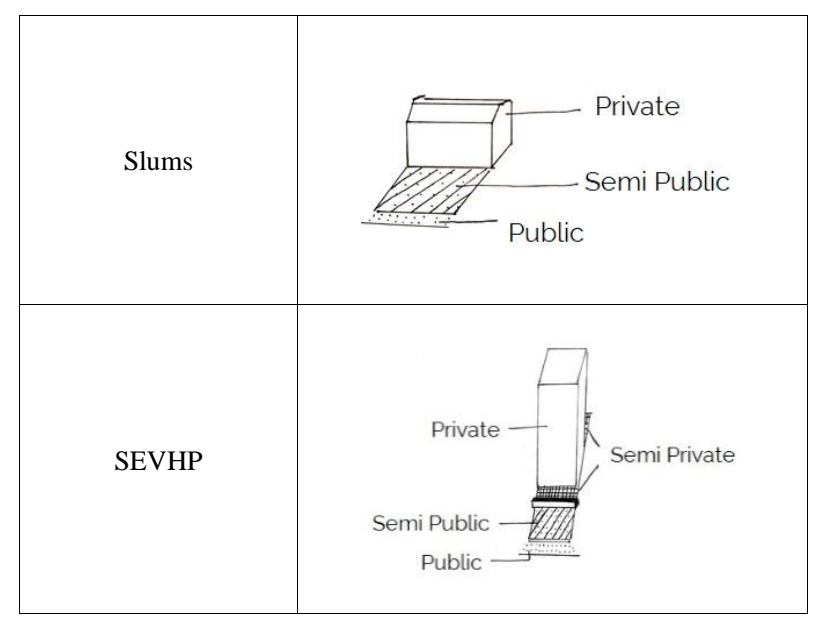

In the case, SEVHP can provide only 1 of 5 elements which promote a contact, while slum settlements provide all of these 5 elements. So, even SEVHP claims to ensure a larger, more secure and luxury environment, it is deficient in providing small scale physical arrangement which is important for human contacts and relations in each other. Table- 6 compares these elements between both habitats.

Additionally, Gehl claimed that just the first few floors of a multi-story building can provide a meaningful relation within the ground level [29]. Moreover the people above the fifth floor are not a part of the scene and cannot endure a real communication with the ground level events. Consequently, SEVHP with 49 storeys also cannot provide a meaningful contact/relation both with the ground level and the slum settlements. On the other hand, slums with their human-scaled and low-storey structure in the pressure and shadow of SEVHP can ensure a meaningful relationship with their environment. Moreover, being as a part of the street scene, these housing contributes to observing and controlling the incidents on the street, even the strangers; without the need of guidance and high borders. 
Table 6. Inner Scale Social Interaction in Buildings(Created by the authors according to Gehl, [29] )

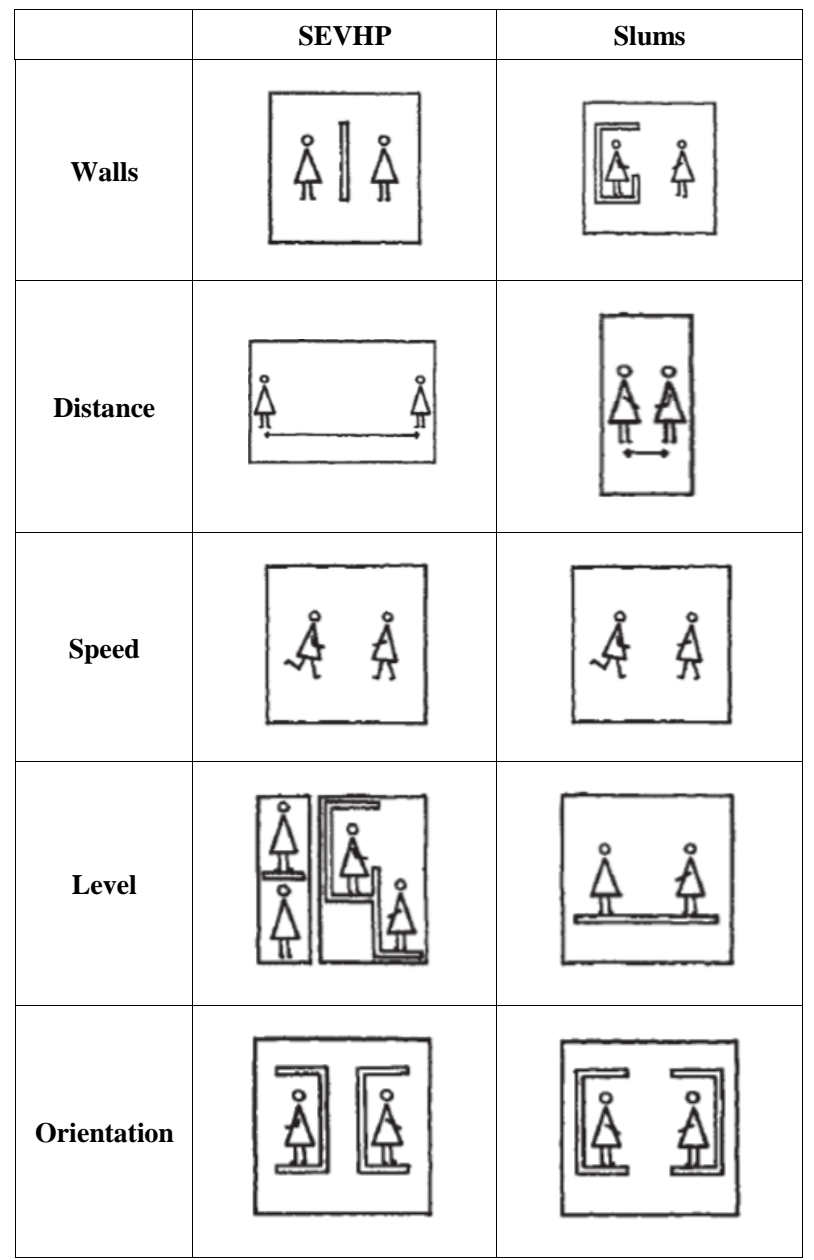

\section{Discussion \& Conclusions}

The most important feature which provides character and peculiarity to cities is their heterogeneous structure. However, this heterogeneity has been dissolved with the changes on socio-economic structures of city and turned into more homogeneous parts which include "like-minded" inhabitants. Each of these homogenous enclaves has their own morphology. Their gates form a dramatic and highly visible manifestation of social fragmentation and polarization [26]. Consequently fragmented parts have very different socio-spatial structures which result in decreasing sense of place of people, although they have been located in close proximity.

As a result of the study, it is observed that each habitat has their own urban life perspective and all of them are reflected to the space scene. This reflection has been analyzed on the classification of a tripartite scale.

At street scale, both habitats control the permeability/accessibility with different elements. While SEVHP has enclosed with walls as physical borders which prevent permeability/accessibility of spaces, slum settlements provide this control without their physical borders in a symbolic way. However slum settlements still achieve to be a part of the street and its control is a natural result of being a neighborhood. Additionally, public spaces which are provided by both territory present different characteristics. SEVHP has several activity spaces inside the borders. Contrary, slum settlement has not public spaces which are designed specifically only for its inhabitants. This unequal distribution of activity areas affects their activity patterns. However it has been observed that the slum inhabitants create and define their own activity spaces organically in a more efficient way.

At plot scale, it is obvious that there are immense transforms when changes on parcel shapes and building numbers in years are investigated. Parcels with private ownership have changed through zoning laws and more than half of the slums have been cleaned from the site. As a consequent, the area becomes more preferable for housing projects such as SEVHP. In addition, there is a huge difference between density of SEVHP and slums. While dense plot of SEVHP affects the neighborhood relations negatively and out of human-scale, slums have more spacious areas and perceivable neighborhood relations because high density of settlements made it inconceivable for the inhabitants of a place to recognize each other.

At building scale, hierarchy of spaces changes due to the perception of the designers of both habitats. Slums settlements generally have not semi-private level of hierarchy because inhabitants want to settle somewhere only, to provide hierarchy is not meaningful for them but when strangers enter the area, feel a hierarchy which has formed organically even it has not walls. However SEVHP's spaces are well-designed and constituted by physical arrangements to accommodate more private life for its inhabitants.

Additionally, inner scale elements such as the height of buildings or orientation of living units can provide a visual or author contact which promotes meaningful relations with inhabitants. Although the design of SEVHP has not allowed to contact between inhabitants, slums include more human-scale interaction elements which have been formed without design concerns.

As a result, it is clear that SEVHP as a representative case of gated communities has literally been enclosed with social/physical walls and designed to promote privileged life for their inhabitants, ignoring the physical and social effect it has left to the outside of these borders. The people around are undesirable for these communities. On the other hand, slums don't have physical borders with defined walls but have unintentional symbolic social walls to the others from outside. Their spatial effects on morphology have also been observed in several scales.

Two different morphologies in the same neighborhood act like the opposite poles of a magnet. Inhabitants of both habitats perceive each other as a danger in a close proximity. It seems that there will be new gated 
communities, and the demolishing of slums will raise in accelerations which results in the increase of the tension between two groups. Additionally, neighborhood relations will decrease within these mini-cities as a consequence of this spatial fragmentation.

Here the question raises should new city designs continue to provide walled islands or it should integrate neighborhoods? These subjects will continue to be discussed inevitably. The need is to lead these transformations in a way that creates a city for everyone instead of a specific group. In the case that it cannot be achieved, social segregation will continue parallel to the spatial segregation. The aim should be designing city that everyone can live together despite their different lifestyles and backgrounds without borders.

\section{Acknowledgements}

This research did not receive any specific grant from funding agencies in the public, commercial, or non-for-profit sectors.

\section{REFERENCES}

[1] Roitman, S. (2005). Who Segregates Whom? The Analysis of a Gated Community in Mendoza, Argentina. Housing Studies: 20:2, 303-321. https://doi.org/10.1080/0267303030 42000331790

[2] Rapoport, A. (1977). Human aspects of urban form: towards a man; environment approach to urban form and design. Oxford: Pergamon Press. https://doi.org/10.1016/C2013-002616-3

[3] Maloutas,T. (2004) "Editorial: Urban Segregation And The

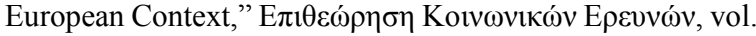
113, no. 113, p. 3. https://doi.org/10.12681/grsr.9214

[4] Stojanovski, T. (2018) Typo-morphology and environmental perception of urban space. ISUF 2018 XXV International conference https://www.researchgate.net/publication/32884 1341_Typo-morphology_and_environmental_perception_o f_urban_space

[5] Ritzer, G. (2007). The Blackwell encyclopedia of sociology. Malden, MA: Blackwell Pub. https://doi.org/10.1002/97814 05165518

[6] Feitosa, F.F. Câmara, G. Monteiro, A. M. V. Koschitzki, T.\& Silva, M.P.S (2007) Global and local spatial indices of urban segregation. International Journal of Geographical Information Science, 21:3, 299-323. https://doi.org/10.1080 $/ 13658810600911903$

[7] Andersen, H. S. (2019). Urban Sores: on the interaction between segregation, urban decay and deprived neighbourhoods. S.1.: Routledge. https://doi.org/10.4324/97 81315191980

[8] Garner, B. A. (2016). Garners modern English usage. New York, NY: Oxford University Press. https://doi.org/10.1093 /acref/9780190491482.001.0001

[9] Caldeira, T. (1996) Fortcified Enclaves: The New Urban Segregation. Public Culture 8 (2): 303-328. https://doi.org/ $10.1215 / 08992363-8-2-303$

[10] Reardon, S., \& O'Sullivan, D. (2004). Measures of Spatial Segregation. Sociological Methodology, 34, 121-162. https://doi.org/10.1111/j.0081-1750.2004.00150.x

[11] Marcuse, P. (2005). Enclaves yes, ghettos no: Segregation and the state. https://www.researchgate.net/publication/291 091410_Enclaves_yes_ghettos_no_Segregation_and_the_st ate

[12] Wirth, L. (1938). Urbanism as a Way of Life. American Journal of Sociology, 44(1), 1-24. www.jstor.org/stable/276 8119

[13] Norton, W., \& Mercier, M. (2016). Human geography. Don Mills, Ontario: Oxford University Press. https://books.goog le.com.tr/books?id=cUB0jwEACAAJ\&hl=tr\&source =gbs_ book_other_versions

[14] Uzun, C. N. (2006). Yeni Yasal Düzenlemeler ve Kentsel Dönüșüme Etkileri. Planlama Dergisi. [New Legal Regulations and Effects on Urban Transformation], Journal of Planning http://www.spo.org.tr/resimler/ekler/b0250793 549726d_ek.pdf

[15] Ghosh, S. (2015). Cities by Design: The Social Life of Urban Form; Explorations in Urban Design: An Urban Design Research Primer; The Nature of Urban Design: A New York Perspective on Resilience, Journal of Urban Technology, 22:3, 121-126.https://doi.org/10.1080/10630732.2015.1078 604

[16] Lefebvre, H. (1970). The Urban Revolution. Minnesota, London: University of Minnesota Press. https://books.googl e.com.tr/books/about/The_Urban_Revolution.html?id=5_db eJX3EPsC\&redir_esc $=\mathrm{y}$

[17] Brotchie, J. F., Newton, P., Hall, P., \& Nijkamp, P. (1985). The future of urban form: the impact of new technology. New York: Kent and Sydney and Nichols Publishing Company. https://doi.org/10.1080/08109028508629010

[18] Madanipour, A. (2007). Designing the City of Reason: Foundations and Frameworks. Rutledge. https://books.goog le.com.tr/books?id=XqN8AgAAQBAJ\&dq=designing+the + city+of+reasons\&hl=tr

[19] Gordon, G. (1984) 'The shaping of urban morphology', Urban History Yearbook pp. 1-10 https://doi.org/10.1017/S 0963926800006878

[20] Birkhamshaw, A., \& Whitehand, J. W. R. (2012). Conzenian urban morphology and the character areas of planners and residents. Urban Design International. https://doi.org/10.10 57/udi.2011.22

[21] Conzen, M. R. G. (1960). Alnwick, Northumberland: A Study in Town-Plan Analysis. Wiley on behalf of The Royal Geographical Society.https://doi.org/10.1177/03091325093 34948

[22] Whitehand, J. W. R. (2007). Conzenian Urban Morphology and Urban Landscapes. İstanbul: 6th International Space Syntax Symposium. http://www.spacesyntaxistanbul.itu.ed u.tr/papers/invitedpapers/jeremy_whitehand.pdf 
[23] Akyol Altun, D . (2010). Kapalı Konut Siteleri ve 'Mahalle' Kavramı. IDEALKENT, 1 (2), 216-244 [Gated Communites and the Concept of 'Neigborhood'], IDEALKENT, 1(2), 216-244. http://dergipark.org.tr/tr/pub/idealkent/issue/3662 $5 / 417025$

[24] Gürer, T. (2016). Tipomorfoloji: Kentsel Mekânın Yapısını Anlamak. İDEALKENT, 7 (18), 8-21. http://dergipark.org.t r/tr/pub/idealkent/issue/36793/419081

[25] Moudon, A.V. (1994). Getting to know the built landscape: Typomorphology. In K.A. Franck, L.H. Schneekloth (Eds.), (1994). Ordering space: Types in architecture and design. New York: Wiley, John \& Sons https://books.google.com.tr /books?id=ykYsc8Uy3LQC\&dq=Getting+to+know+the+bu ilt+landscape $\& h l=t r \& s o u r c e=g b s \_n a v l i n k s \_s$

[26] Carmona, M., Tiesdell, S., Heath, T., \& Oc, T. (2010). Public places, urban spaces the dimensions of urban design. London: Routledge. ISBN: 978-1136020490https://books.g oogle.com.tr/books/about/Public_Places_Urban_Spaces.ht $\mathrm{ml}$ ?id=J14pLk08icYC\&source=kp_cover\&redir_esc $=\mathrm{y}$

[27] Wilson, E O (1984) Biophilia. Harvard University Press, Cambridge, MA. ISBN: $9780674045231 \mathrm{https} / / /$ books.goog le.com.tr/books/about/Biophilia.html?id=BapY4GLfMOA C\&redir_esc $=\mathrm{y}$

[28] Shaftoe, H. (2012). Convival Urban Spaces-Creating Effecitve Public Spaces. London: Earthscan. ISBN-13: 978-1844073887 https://books.google.com.tr/books/about/ Convivial_Urban_Spaces.html?id=oYxfCzYOpNwC\&redir _esc=y
[29] Gehl, J., \& Koch, J. (2011). Life between buildings: using public space. Washington, DC: Island Press. ISBN-10: 9781597268271 https://books.google.com.tr/books/about/Li fe_Between_Buildings.html?id=X707aiCq6T8C\&redir_esc $=\mathrm{y}$

[30] Ng, E. (2009). Designing High-Density Cities: For Social and Environmental Sustainability. Hoboken: Taylor and Francis. ISBN: 9781849774444 https://books.google.com.tr /books/about/Designing_High_Density_Cities.html?id=oTh ZvLKMnCYC\&source=kp_cover\&redir_esc $=y$

[31] Skjaeveland, O. and Garling, T. (1997). Effects of interactional space on neighbouring. Journal of Environmental Psychology, 181-198. https://doi.org/10.100 6/jevp.1997.0054

[32] Newman, 0. (1973). Defensible Space: People and Design in the Violent City. London, Architectural Press ISBN: 978-0851391366 https://books.google.com.tr/books/about/ Defensible_Space.html?id=D1aZPwAACAAJ\&redir_esc $=$ $\mathrm{y}$

[33] Newman, O. (1996) Creating Defensible Space. DIANE Publishing ISBN: 9780788145285 https://books.google.co $\mathrm{m}$. tr/books/about/Creating_Defensible_Space.html?id=80w 0GEh4ffEC\&redir_esc=y

[34] Dear, M. J. \& Wolch, J.R. (2014). Landscapes of Despair: From Deinstitutionalization to Homelessness (Princeton Legacy Library) ISBN: 978-0691631110 https://doi.org/10. 2307/j.ctt7ztv60 